\title{
Foreign Direct Investment, Economic Growth and Employment: Evidence from China
}

\author{
Yugang $\mathrm{He}^{1}$ \\ ${ }^{1}$ Department of International Trade, College of Business, Chonbuk National University, Jeonju, South Korea \\ Correspondence: Yugang He, Chonbuk National University, Jeonju, South Korea.
}

Received: January 13, 2018

Accepted: February 3, $2018 \quad$ Online Published: February 28, 2018

doi:10.20849/iref.v2i1.320

URL: https://doi.org/10.20849/iref.v2i1.320

\begin{abstract}
This paper applies the annual data series from 1983 to 2016 and introduces an employment variable to analyze the interaction among foreign direct investment, economic growth and employment. Three variables are used to conduct an empirical analysis under the VAR model. Via the analysis of Augmented Dickey-Fuller test, Granger causality test, impulse response function and variance decomposition, the results show that the foreign direct investment has a positive effect on economic growth and employment, and the economic growth has a positive effect on employment. The employment and economic growth exist bidirectional causality. Meanwhile, the foreign direct investment can also result in an increase in the employment. More importantly, this paper provides some ideas for China's government to settle some social problems such as employment and economic growth. Specifically, at present, China's government still should encourage foreign investors to invest in China because it can be beneficial to employment and economic growth in China. Of course, the structure of employment also should be optimized so as to keep high speed economic growth. Simultaneously, the high speed economic growth can improve the employment in China.
\end{abstract}

Keywords: foreign direct investment, economic growth, employment, VAR model

\section{Introduction}

In 2014, the ministry of commerce in China has reported that the scale of foreign direct investment has been ranked first in the world. As a matter of fact, in 1983, the amount of foreign direct investment in China is only 920 million dollar, but in 2016, the amount of foreign direct investment in China is greatly up to 133843.02 million dollar. In other words, its average annual growth rate is $413 \%$. This great achievement owes to the reform and opening-up policy. Also, the foreign direct investment is an important economic variable. It is one of most significant channels for the world to affect all aspects of China such as the economic growth and the employment. This paper tries to explore the interaction of foreign direct investment to the economic growth and the employment.

The foreign direct investment has been regarded as one of the important factors that stimulate the economic growth and the employment in most of the developed countries. However, fewer studies have explored this issue in the case of developing countries. This study examines the interaction among foreign direct investment, economic growth and employment in China. At present, the economic growth and the employment are the most troublesome problems which are needed to be solved in China. Therefore, this paper applies time series data from the period of 1983 to 2016 and uses the vector auto regression model to hunt for the operating mechanism among them. Via conducting an empirical analysis, the findings reveal satisfactory evidences that there is a positive and significant impact of foreign direct investment on economic growth and employment in China.

To this end, the rest of this paper is organized as follows: Part II reviews a summary of empirical studies which are explored by the previous scholars concerning this issue. Part III discusses the model and data. Part IV presents the empirical results. Part V provides the conclusion.

\section{Literature Review}

Despite the multitude of studies about the interaction among foreign direct investment and economic growth as well as employment, there are no common consensuses regarding this issue between different studies, so working on this issue is still required. The absence of common consensus can be due to the different time periods, countries and econometric method employed in these studies. 
Katircioglu (2009) investigates the causality relationship between foreign direct investment inflows and economic growth for Turkey over 1970 to 2005 . The results of causality indicate unidirectional causality from GDP growth to foreign direct investment in the long run. Kersan and Zubin (2009) determine the impact of foreign direct investment on macroeconomic indicators (GDP, Employment and Export) of the Croatian economy. The results indicate that the foreign direct investment has a negative effect on employment while it does not have an effect on GDP growth. So, the positive expected effect has failed because of the low share of Greenfield investments. Miankhel, Thangavelu, and Kalirajan (2009) employ a VECM framework for examining the causality between foreign direct investment and GDP for six emerging countries (Chile, India, Mexico, Malaysia, Pakistan and Thailand). The results of long-run investigations indicate the existence of causality from GDP to other variables such as foreign direct investment in the case of India. The results indicate bidirectional causality between GDP and foreign direct investment in Malaysia. The findings also show causality between foreign direct investment and GDP in Latin American countries. Liu (2009) applies annual data from 1983 to 2005 to investigate the relationship between foreign direct investment and economic growth in China. His results show that the contribution of foreign direct investment to economic growth is continuously decreasing since 1994.

Ge (2010) uses the annual data from 1978 to 2005 to study the relationship between employment and economic growth in China. He finds that the employment has a great effect on economic growth. Conversely, the economic growth has a little effect on employment.

Umoh, Jacob and Chuku (2012) examine Nigerian economic growth and foreign direct investment relationship. They identify a bidirectional relationship between economic growth and foreign direct investment. Employing single and simultaneous equation systems, the results reveal joint determination of foreign direct investment and economic growth with a positive feedback from foreign direct investment to growth and from growth to foreign direct investment. El-Wassal and Amal (2012) reveal that in many Arab countries sectorial composition of foreign direct investment (as financial development, trade openness, human capital and quality of infrastructure) has played a critical role in the growth of foreign direct investment, which may be a necessary prerequisite for foreign direct investment to promote economic growth in these countries. Anicethkato (2012) tries to analyze the impact of foreign direct investment inflows on employment generation or creation of Tanzania. His study specifically estimates the effect of foreign direct investment on employment creation in Tanzania for the period of 1990 to 2008. His results show that the foreign direct investments have a big significant impact on the pattern of employment opportunities. Sauwaluck (2012) reveals that there is a strong and positive impact of foreign direct investment on South Korean economic growth. The employment also has a positive impact on South Korean economic growth. The interaction effects of foreign direct investment and foreign direct investment indicate that the transfer of high technology and knowledge has an adverse impact on South Korean economic growth. He and $\mathrm{Xu}$ (2012) conduct cointegration test, Granger causality test and vector error correction model to analyze the linkage between foreign direct investment and economic growth in China. They obtain the results that the foreign direct investment has a certain positive effect on economic growth whenever in the long run or in the short run.

Kim and Jang (2013) set Suzhou as an example in China. Suzhou is positioned right in the heart of the Chang Jiang triangle, and it is one of the most economic advanced cities in Southern Jiang Su region. Meanwhile, Suzhou also enjoys the most foreign direct investments. So, they focus much on foreign direct investments' conditions and positive or negative impacts on Suzhou' economic growth through means such as various data and expert opinions. This article is a good guide on how to further improve the work of attracting companies, and provides excellent suggestions on the continual development of Suzhou. Najat, Shivee and Normaz (2013) examine that the linkage between foreign direct investment and economic growth among southern african customs union countries. Using dynamic ordinary least square, their finding shows that foreign direct investment has a positive and significant impact on economic growth of southern african customs union countries.

Bagli and Adhikary (2014) find that five most developed Asian countries have reported a positive impact of foreign direct investment on economic growth and it is as a result of opening their economies and improving the environment for investment of foreign investors. Stylianou (2014) figures that if we analyze foreign direct investment in developed countries (like USA), we can understand that the main determinant in economic growth, whether in short or long term, is a perfect relationship between foreign direct investment and U.S. exports. Xie (2014) uses the panel regression and DEA to the impact of capital, labor and foreign direct investment on economic growth in China. He finds that the impact of foreign direct investment is not so significant on economic growth when compared with that of capital and labor in recent years.

Kim and Kim (2016) investigate the roles which are played by foreign direct investment in determining China's 
fast growth and regional inequality during the period 1987-2014. They use the panel data and divide China into four major regions (Eastern, Central, West, and Northeast). Their results show that foreign direct investment in the eastern region appears the greatest impact on economic growth among all regions. However, the northeastern region shows the smallest.

$\mathrm{Li}$ and $\mathrm{Xu}$ (2017) make use of the annual data from 1995 to 2015 to analyze the dynamic relationship between employment and economic growth in China. Via empirical analysis they find that the economic growth has a positive effect on employment. Wang (2017) finds that there is a mutual effect between economic growth and employment. Namely, an increase in the economic growth can result in an increase in the employment. Meanwhile, an increase in the employment can also lead to an increase in the economic growth.

In summary, from the previous researches, some differences between this paper and previous researches can be reached. These differences fall into three categories: The first difference is that some scholars only focus on the impact of foreign direct investment on economic growth such as Bagli and Adhikary (2014), El-Wassal and Amal (2012), Katircioglu (2009) and Liu (2009). The second difference is that a number of experts mainly pay attention to the impact of employment on economic growth such as $\mathrm{Li}$ and $\mathrm{Xu}$ (2017), Wang (2017) and Ge (2010). The third difference is that a few scholars try their best to study the impact of foreign direct investment on employment just as Anicethkato (2012). In order to distinguish with them, this paper is based on these previous studies to perform a new attempt. This paper combines these three variables to establish a dynamic relationship among them. By applying the vector autoregressive model, in this paper, great efforts are expand to demonstrate the dynamic interaction among foreign direct investment, economic growth and employment. Finally, a three-variable VAR is estimated (foreign direct investment, economic growth, and employment) so as to make their interaction most clear.

\section{Method}

Vector autoregression (VAR) is a stochastic process model used to capture the linear interdependencies among multiple time series. VAR models generalize the univariate autoregressive model (AR model) by allowing for more than one evolving variable. All variables in a VAR enter the model in the same way: each variable has an equation explaining its evolution based on its own lagged values, the lagged values of other model variables, and an error term. VAR modeling does not require as much knowledge about the forces influencing a variable as do structural models with simultaneous equations: The only prior knowledge required is a list of variables which can be hypothesized to affect each other intertemporally. More importantly, there are some advantages of vector autoregression. The first is that VAR model does not need to specify which variables are endogenous or exogenous because all are endogenous. The second is that VAR model allows the value of a variable to depend on its own lags and the lags of other variables. Models thus offer a rich structure which may be able to capture more characteristics of the data. The third is that assuming there are no contemporaneous terms on the right hand side of VAR, ordinary least square can be used separately on each equation to estimate the system. This is because all the variables on the right hand side are predetermined. For example, at time they are known. It can be shown that ordinary least square will be consistent, asymptotically efficient and asymptotically normal. The final is that forecasts generated by VAR model are often better than conventional structural models.

Due to these advantages mentioned above, in this paper VAR model is determined to be used to analyze the nexus between foreign direct investment and economic growth and employment in China. VAR model is one of most significant models that can be utilized to systematically forecast the interconnection among random disturbance and analyze the dynamic effect of variable system. Moreover, the variance decomposition will be made use of to recognize these impulses so as to explain the impacts of different kinds of economic impulses on economic variables. Mathematical expression of $\operatorname{VAR}(\mathrm{p})$ model gives:

$$
y_{t}=\alpha_{1} y_{t-1}+\alpha_{2} y_{t-2}+\alpha_{3} y_{t-3}+\ldots+\alpha_{p} y_{t-p}+\beta x_{t}+\varepsilon_{t}
$$

Where $y_{t}$ is the vector of $k$-dimension endogenous variable; $x_{t}$ is the vector of $d$-dimension exogenous variables; $p$ is the number of lag orders; $\alpha_{1}, \alpha_{2}, \alpha_{3}$ and $\beta$ are estimated coefficients; $\varepsilon_{t}$ is the white noise.

Another important factor that should be taken into consideration is that the foreign direct investment has little effect on agricultural industry (primary industry). If the total GDP is directly used without any distinction, it will be probably that the impact of foreign direct investment will be undervalued on economic growth and employment. So, in this paper, the sum of manufacturing industry and tertiary industry is regarded as an index of economic growth. And the employment figure is the total people who work in manufacturing industry and 
tertiary industry. If GDP and employment figure of three industries are directly applied, the effect of foreign direct investment on economic growth and employment may be undervalued.

\section{Empirical Analysis}

\subsection{Data Description}

This paper adopts three variables (foreign direct investment, economic growth and employment). Their time span is from 1983 to 2016. All of them are sourced from the National Bureau of Statistic of the People's Republic of China. They will be shown in Table 1.

Table 1. Raw data

\begin{tabular}{|c|c|c|c|}
\hline Year & Real FDI (RMB: billion) & GDP (RMB: billion) & Employment (Number: ten thousand) \\
\hline 1983 & 1.82 & 406.00 & 15285.60 \\
\hline 1984 & 3.30 & 498.29 & 117329.50 \\
\hline 1985 & 5.67 & 655.72 & 118743.50 \\
\hline 1986 & 7.73 & 761.21 & 120027.00 \\
\hline 1987 & 8.61 & 897.02 & 121121.00 \\
\hline 1988 & 11.89 & 1134.92 & 122085.00 \\
\hline 1989 & 12.77 & 1295.15 & 122105.00 \\
\hline 1990 & 16.68 & 1385.57 & 125834.90 \\
\hline 1991 & 23.24 & 1671.68 & 126392.90 \\
\hline 1992 & 60.70 & 2139.42 & 127453.10 \\
\hline 1993 & 158.51 & 2878.57 & 129128.30 \\
\hline 1994 & 291.03 & 3916.56 & 130827.00 \\
\hline 1995 & 313.34 & 4931.94 & 132535.10 \\
\hline 1996 & 346.91 & 5793.53 & 134130.30 \\
\hline 1997 & 375.17 & 6544.98 & 134979.80 \\
\hline 1998 & 376.39 & 7075.68 & 135459.80 \\
\hline 1999 & 333.77 & 7601.54 & 135625.60 \\
\hline 2000 & 337.10 & 8556.27 & 136042.50 \\
\hline 2001 & 388.01 & 9536.07 & 136398.50 \\
\hline 2002 & 436.53 & 10552.72 & 136640.00 \\
\hline 2003 & 442.86 & 12045.18 & 137531.60 \\
\hline 2004 & 501.82 & 14093.58 & 146937.50 \\
\hline 2005 & 494.16 & 16551.22 & 148174.40 \\
\hline 2006 & 50238 & 19612.15 & 141205.20 \\
\hline 2007 & 568.55 & 24244.43 & 143037.40 \\
\hline 2008 & 641.69 & 28676.24 & 144590.60 \\
\hline 2009 & 615.02 & 31491.96 & 146937.50 \\
\hline 2010 & 715.74 & 37366.78 & 148174.40 \\
\hline 2011 & 749.29 & 44313.74 & 149825.80 \\
\hline 2012 & 705.21 & 48946.52 & 150931.00 \\
\hline 2013 & 728.23 & 53991.54 & 152806.00 \\
\hline 2014 & 734.45 & 58563.04 & 154463.00 \\
\hline 2015 & 786.44 & 62819.00 & 155532.00 \\
\hline 2016 & 869.98 & 68045.70 & 159477.00 \\
\hline
\end{tabular}

Source: National Bureau of Statistics of the People's Republic of China. 
As for the empirical analysis, the VAR is established to analyze the linkage between foreign direct investment and economic growth and employment. And in order to remove the impact of heteroscedasticity, all variables are taken as the logarithm form. $\log F D I$ stands for the foreign direct investment; $\log G D P$ stands for the economic growth; $\log E F$ stands for the employment. All data-sets are obtained from the National Bureau of Statistics of the People's Republic of China. All of them will be shown in Table 2.

Table 2. Variables and their definitions

\begin{tabular}{lll}
\hline Variable & Definition & Source \\
\hline $\log F D I$ & real use of foreign direct investment & $\begin{array}{l}\text { National Bureau of Statistics of the People's } \\
\text { republic of China }\end{array}$ \\
$\log G D P$ & $\begin{array}{l}\text { sum of manufacturing industry and tertiary } \\
\text { industry }\end{array}$ & $\begin{array}{l}\text { National Bureau of Statistics of the People's } \\
\text { republic of China }\end{array}$ \\
$\log E F$ & total people who work in manufacturing & $\begin{array}{l}\text { National Bureau of Statistics of the People's } \\
\text { republic of China }\end{array}$ \\
\hline
\end{tabular}

\subsection{Unit Root Test}

A time-series regression approach is used to study the relationship among time series. The first step should be conducted is that the stationary of the original sequence must be tested. The reason is that, even though the sequence is non-stationary, the result of regression test finds that the relationship among different sequences may be notable. In fact, this kind of regression is spurious regression. Therefore, it is necessary to test the stationary of the logarithm sequence of variables.

The $A D F$ test is completed by the following three models:

Model 1:

$$
\Delta X_{t}=\delta X_{t-1}+\sum_{i=1}^{m} \beta_{i} \Delta X_{t-1}+\varepsilon_{t}
$$

Model 2:

$$
\Delta X_{t}=\alpha+\delta X_{t-1}+\sum_{i=1}^{m} \beta_{i} \Delta X_{t-1}+\varepsilon_{t}
$$

Model 3:

$$
\Delta X_{t}=\alpha+\beta t+\delta X_{t-1}+\sum_{i=1}^{m} \beta_{i} \Delta X_{t-1}+\varepsilon_{t}
$$

The null hypothesis, $H_{0}: \delta=0$, one unit root exists; An alternative hypothesis, $H_{1}: \delta \neq 0$, a unit root does not exist.

The difference between model 1 and the other two models is that the model 2 has a constant and the model 3 has a constant and trend term. Actually, the proper order to test the sequence is from the model 3 to the model 1 . Any test that rejects the null hypothesis means that its original sequence does not have a unit root. As long as one of the result from any of the models rejects the null hypothesis, the original hypothesis can be considered as stationary. When all of the testing results of the three models do not reject the null hypothesis, the original sequence can be considered as non-stationary. And then, the first order difference sequence of the original sequence should be tested, and the procedures above should be repeated.

Table 3 shows the unit root test of the original sequence and its first difference. 
Table 3. Result of unit root test

\begin{tabular}{lccc}
\hline Variable & ADF Test Statistic & P-Value & Test critical value 5\% \\
\hline $\log F D I$ & -2.890 & 0.058 & -2.960 \\
$\log G D P$ & -2.341 & 0.167 & -2.948 \\
$\log E F$ & 0.364 & 0.978 & -2.957 \\
$D \log F D I$ & -3.929 & 0.006 & -2.981 \\
$D \log G D P$ & -3.064 & 0.040 & -2.960 \\
$D \log E F$ & -319.346 & 0.000 & -2.957 \\
\hline
\end{tabular}

Description: $D$ represents the first difference of all variables.

Table 3 shows all variables are non-stationary under the 5\% significance level. However, after first difference, all of them become stationary under the $5 \%$ significance level.

\subsection{Establishment of VAR Model}

When a VAR model is established, the optimal lag should be confirmed. The results are shown in Table 4.

Table 4. VAR model lag order selection criteria

\begin{tabular}{lcccccc}
\hline Lag & LogL & LR & EPE & AIC & SC & HQ \\
\hline 0 & 243.576 & NA & $3.65 \mathrm{e}-11$ & -15.521 & -15.382 & -15.476 \\
1 & 263.552 & $34.797^{*}$ & $1.80 \mathrm{e}-11^{*}$ & $-16.229^{*}$ & $-15.674^{*}$ & $-16.048^{*}$ \\
2 & 272.352 & 13.626 & $1.86 \mathrm{e}-11$ & -16.216 & -15.245 & -15.900 \\
\hline
\end{tabular}

${ }^{*}$ indicates lag order selected by the criterion.

According to AIC and SC, lag1 is optimal. After confirming the optimal lag, VAR(1) model is established and its estimated regression results show in Table 5.

Table 5. Coefficients of variables

\begin{tabular}{lcccc}
\hline Variable & $\log F D I_{t-1}$ & $\log G D P_{t-1}$ & $\log E F_{t-1}$ & $C$ \\
\hline $\log F D I_{t}$ & 0.953 & -0.043 & -0.036 & 0.534 \\
$\log G D P_{t}$ & 0.010 & 0.966 & 0.004 & 0.173 \\
$\log E F_{t}$ & -0.007 & 0.063 & 0.003 & 4.896 \\
\hline
\end{tabular}

The specific equation gives:

$$
\begin{gathered}
\log F D I_{t}=0.534+0.953 \log F D I_{t-1}-0.043 \log G D P_{t-1}-0.036 \log E F_{t-1}+\varepsilon_{t} \\
\log G D P_{t}=0.173+0.010 \log F D I_{t-1}+0.966 \log G D P_{t-1}+0.004 \log E F_{t-1}+\varepsilon_{2 t} \\
\log E F_{t}=4.896-0.007 \log F D I_{t-1}+0.063 \log G D P_{t-1}+0.003 E F_{t-1}+\varepsilon_{3 t}
\end{gathered}
$$

From Table 5, the t-statistic value of most estimated coefficients is significant under 5\% significant level in the regression model above. Although few estimated coefficients are not significant, still the VAR(1) model is applied. The reason is that the insignificant estimated coefficients may be caused by the multiple linear regression. Another important thing that should be conducted is to test the stability of estimated model. If the estimated model is not steady, some estimated results will lose their effectiveness just as the standard error of the impulse response function. In this paper, AR root will be used to test stability of estimated model. Namely, the 
reciprocal of all roots of estimated model is less than one, which indicates that the estimated model is steady. The result is shown in Figure 1.

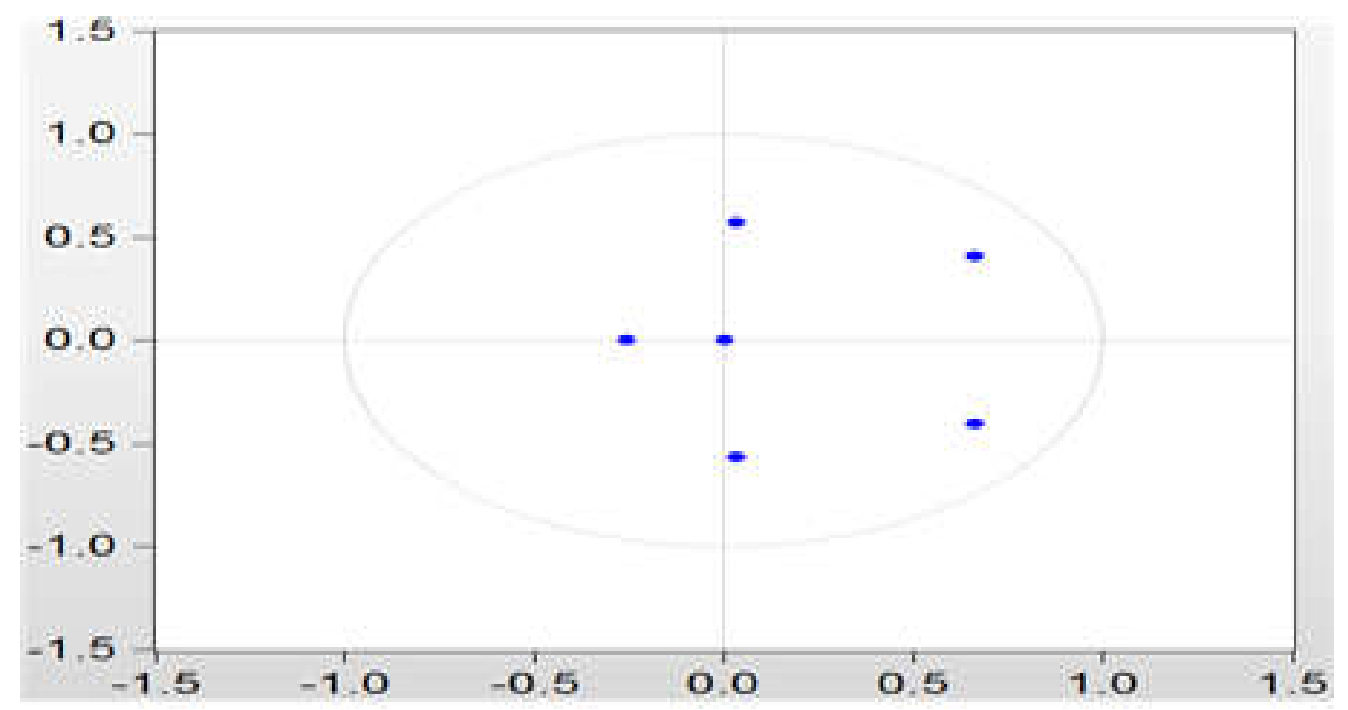

Figure 1. Inverse roots of AR characteristic polynomial

Figure 1 shows that all units roots locate inside unit circle. So, the estimated model is steady. Also, it demonstrates a long-run relationship among three variables. Thus, the Granger causality test, the impulse response function and the decomposition variance are used to analyze the interaction among three variables.

\subsection{Granger Causality Test}

The Granger causality teat will be conducted as to make the dynamic relationship among foreign direct investment, economic growth and employment more clear. The results of the Granger causality test will be shown in Table 6.

Table 6. Pairwise granger causality tests

\begin{tabular}{lcccc}
\hline lag & Null Hypothesis & Obs & F-Statistic & Prob. \\
\hline 2 & $\log F D I$ does not Granger Caus $\log G D P$ & 31 & 3.665 & 0.040 \\
2 & $\log G D P$ does not Granger Cause $\log F D I$ & 31 & 1.557 & 0.230 \\
2 & $\log F D I$ does not Granger Cause $\log E F$ & 31 & 4.246 & 0.025 \\
2 & $\log E F$ does not Granger Cause $\log F D I$ & 31 & 1.056 & 0.362 \\
2 & $\log E F$ does not Granger Cause $\log G D P$ & 31 & 5.390 & 0.007 \\
2 & $\log G D P$ does not Granger Cause $\log E F$ & 31 & 6.190 & 0.003 \\
\hline
\end{tabular}

Table 6 shows the hypothesis that $\log F D I$ does not Granger Cause $\log G D P$ is rejected under $5 \%$ significant level. It means that a unidirectional causality between foreign direct investment end economic growth exists under 5\% significant level. In other word, the foreign direct investment is an important factor to promote the economic growth in the long run in China. Moreover, this conclusion is in accordance with cointegration results. At present, China's government still needs to take measures to attract foreign investors to invest in China.

Table 6 also implies that there is a long-run equilibrium relationship between foreign direct investment and employment. A unidirectional causality from foreign direct investment to employment exists. The hypotheses that $\log F D I$ does not Granger Cause $\log E F$ is rejected and $\log E F$ does not Granger Cause $\log F D I$ is one-rejected under $5 \%$ significant level. It demonstrates that the foreign direct investment not only promotes the economic growth but also promotes the employment in China.

Taking the long-run relationship between the economic growth and employment into account, two-way causality 
between employment end economic growth exists under 5\% significant level. Namely, the employment and the economic growth have mutual promoted effects. And Granger causality test result is in keeping with the result of cointegration test.

\subsection{Impulse Response Function}

In shock processing, the impulse response function of a dynamic system is its shock offering when presented with a brief shock suffering, called an impulse. More generally, an impulse response function is the reaction of any dynamic system in response to some external change. In both cases, the impulse response function describes the reaction of the system as a function of time (or possibly as a function of some other independent variable that parameterizes the dynamic behavior of the system). In this paper, the results of impulse response function show in Figure 2.

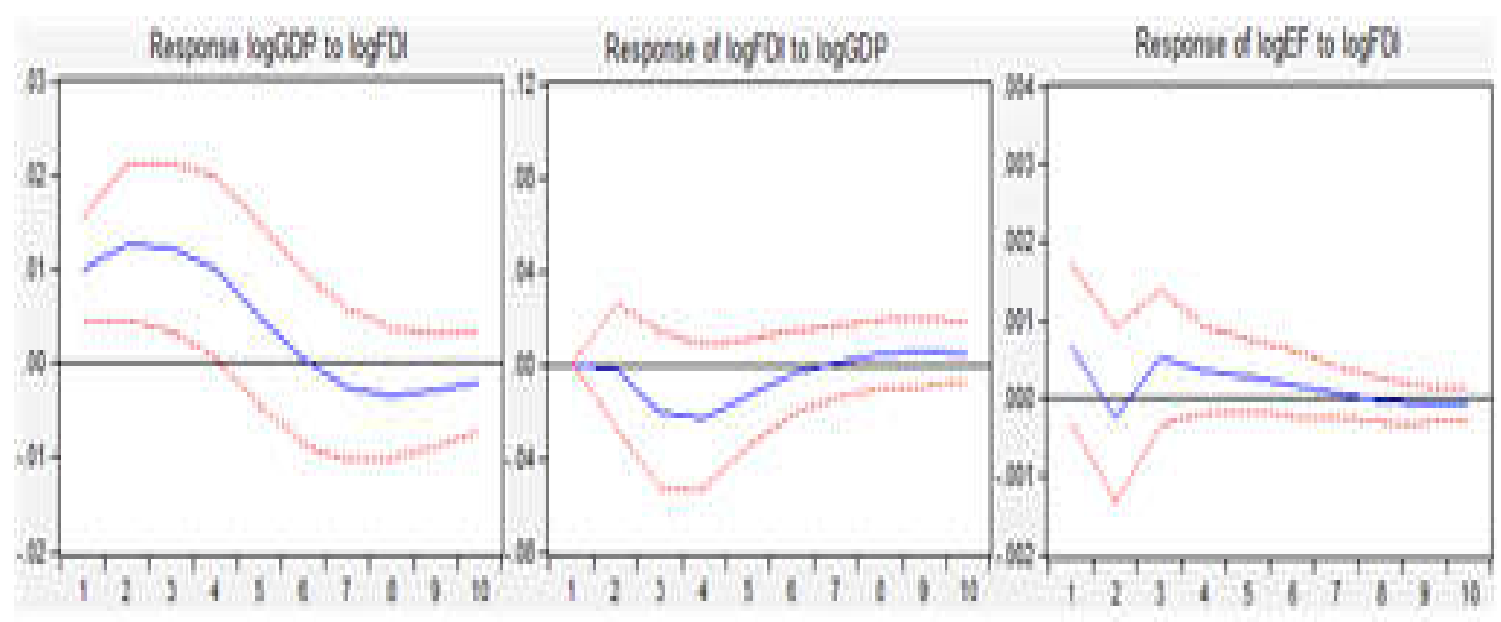

Figure 2. Impulse response function

For response $\log G D P$ to $\log F D I$, when a positive impulse is attached to the foreign direct investment, the economic growth fluctuates up and down in the short run. In the second period, the economic growth arrives at top (positive). After this period, it starts to converge. This indicates that the foreign direct investment has hysteresis effect on economic growth in the short run. An increase in the foreign direct investment results in an increase in the economic growth. However, the effect of foreign direct investment on economic growth will become weak in the long run. And the effect of foreign direct investment on economic growth is positive from period one to period six, and gets top (positive) in second period and gets bottom (negative) in eighth period. Since tenth period, the effect of foreign direct investment on economic growth become positive, but it becomes weaker than that of before. In sum, a positive impulse is attached to the foreign direct investment, which has a greater effect on economic growth in the short run. Still, it exists volatility. As a whole, the foreign direct investment has a positive effect on economic growth.

For response $\log E F$ to $\log F D I$, when a positive impulse is attached to foreign direct investment, the employment has a few fluctuations. And it arrives at bottom (negative) in the second period and arrives at top (positive) in the third period. After third period, it starts to converge. Because the entrance form, the purpose and the industry of foreign direct investment are different, it will exist the structure problems in the short run, which has positive effect on employment. However, an increase in the foreign direct investment results in an increase in the employment in China.

For response $\log F D I$ to $\log G D P$, when a positive impulse is attached to economic growth, the foreign direct investment fluctuates up and down. It indicates that it is difficult to come into conclusion that an increase in the economic growth leads to an increase in the foreign direct investment. In fact, affecting the inflow and the growth of foreign direct investment is very complicated including macro economic and micro economic such as the exchange rate fluctuation, the change of cost and the political. All of them can affect the foreign direct investment.

\subsection{Decomposition Variance}

In econometrics and other applications of time series analysis, a variance decomposition is used to aid in the interpretation of a vector error correction model once it has been fitted. The variance decomposition indicates the 
amount of information each variable contributes to the other variables. It determines how much of the forecast error variance of each of the variables can be explained by exogenous shocks to the other variables. The results of variance decomposition show in Table 7, Table 8 and Table 9.

Table 7. Decomposition variance of $\log F D I$

\begin{tabular}{lllll}
\hline Period & S.E. & $\log F D I$ & $\log G D P$ & $\log E F$ \\
\hline 1 & 0.082 & 100.000 & 0.000 & 0.000 \\
2 & 0.103 & 99.635 & 0.016 & 0.349 \\
3 & 0.113 & 96.305 & 3.165 & 0.530 \\
4 & 0.118 & 90.881 & 6.668 & 2.451 \\
5 & 0.120 & 88.067 & 7.671 & 4.261 \\
6 & 0.121 & 87.643 & 7.663 & 4.695 \\
7 & 0.122 & 87.841 & 7.532 & 4.627 \\
8 & 0.123 & 87.901 & 7.515 & 4.585 \\
9 & 0.123 & 87.750 & 7.617 & 4.632 \\
10 & 0.123 & 87.563 & 7.718 & 4.719 \\
\hline
\end{tabular}

Table 7 indicates that in the first period the fluctuation of foreign direct investment is affected only by itself. The impulse (contribution degree of forecasting error) of economic growth and employment to the foreign direct investment appears from second period. Also when compared with itself impulse, these impulses to foreign direct investment are very weak and it will become stronger as time goes by. However, all the impulse to the foreign direct investment will be kept steady in eighth period (87.9\% from itself, $7.5 \%$ from economic growth, and $4.6 \%$ from employment). In short, the impulse of fluctuations of economic growth and employment to the foreign direct investment are relative weak. Maybe the reason is that there are many factors affect the foreign direct investment whatever macroeconomics or microeconomics. So, there is a limit of economic growth and employment to affect the foreign direct investment.

Table 8. Decomposition variance of $\log G D P$

\begin{tabular}{lcccc}
\hline Period & S.E. & $\log F D I$ & $\log G D P$ & $\log E F$ \\
\hline 1 & 0.017 & 33.464 & 66.536 & 0.000 \\
2 & 0.024 & 46.270 & 40.486 & 13.245 \\
3 & 0.027 & 55.220 & 33.859 & 10.921 \\
4 & 0.030 & 55.816 & 32.128 & 11.056 \\
5 & 0.031 & 55.951 & 31.424 & 12.625 \\
6 & 0.031 & 55.260 & 31.544 & 13.195 \\
7 & 0.031 & 55.313 & 31.410 & 13.278 \\
8 & 0.031 & 55.791 & 31.040 & 13.169 \\
9 & 0.032 & 56.146 & 30.810 & 13.044 \\
10 & 0.032 & 56.215 & 30.755 & 13.031 \\
\hline
\end{tabular}

Table 8 shows that the economic growth is affected by itself and the foreign direct investment in the first period. But the impulse from itself is bigger than that of the foreign direct investment. Moreover, in the following periods, itself impulse will become weaker. Oppositely, the impulse of foreign direct investment will become stronger. It reveals that the impact of foreign direct investment on economic growth has a hysteresis effect, which agrees with the previous. However, from seventh period, all impulses of them trend to be steady (55.3\% from foreign direct investment, $31.4 \%$ from itself, and $13.3 \%$ from employment). In sum, it demonstrates that 
the foreign direct investment has leading role in economic growth.

Table 9. Decomposition variance of $\log G D P$

\begin{tabular}{lcccc}
\hline Period & S.E. & $\log F D I$ & $\log G D P$ & $\log E F$ \\
\hline 1 & 0.002873 & 5.537 & 2.063 & 92.401 \\
2 & 0.002911 & 6.092 & 2.432 & 91.476 \\
3 & 0.002962 & 8.870 & 2.700 & 88.430 \\
4 & 0.002987 & 10.041 & 2.892 & 87.067 \\
5 & 0.003002 & 10.737 & 3.049 & 86.214 \\
6 & 0.003014 & 10.987 & 3.355 & 85.658 \\
7 & 0.003019 & 11.002 & 3.424 & 85.574 \\
8 & 0.003020 & 11.009 & 3.432 & 85.560 \\
9 & 0.003021 & 11.080 & 3.430 & 85.490 \\
10 & 0.003023 & 11.153 & 3.428 & 85.419 \\
\hline
\end{tabular}

Table 9 indicates that the employment is affected by itself, the foreign direct investment and the economic growth in the first period. But the biggest impulse is from itself. This maybe has a direct connection with human capital structure in China. However, as time goes by, the current employment has a weak impact on its following periods. Table 8 also reveals that the impulse of foreign direct investment is stronger than that of economic growth to the employment. Up to tenth period, all impulses to employment are relative steady $(11.2 \%$ from foreign direct investment, $3.4 \%$ from economic growth, and $85.4 \%$ from itself). Meanwhile it also explains that the foreign direct investment has a positive effect on the employment.

\section{Conclusion}

This paper concentrates much on the interaction between foreign direct investment and economic growth and employment based on VAR model. Via empirical analysis, some conclusions are obtained as following gives: Through empirical analysis, the foreign direct investment has a hysteresis effect on economic growth in the short run. It indicates that the increase in the foreign direct investment plays a leading role in economic growth in the short run. In the long run, its effect on economic growth becomes weaker and weaker. It verifies that the policy of introduction of foreign capital to promote economic growth in China is very useful since the reform and opening-up policy. More specifically, the results of Granger causality test show that foreign direct investment plays a vital role in economic growth. Furthermore, it also can be beneficial to the employment. The employment and the economic growth have a mutual promoted-effect on each other. For the impulse response function, GDP in China has a positive effect on itself and seen from the long run, its effect on itself will become from negative to positive. Also, the foreign direct investment in China has a negative effect on GDP in the short run and has a positive effect in the long run. Conversely, the employment in China has a negative effect on GDP. Even though the employment has a positive effect on GDP in the short run, its effect still keeps negative in the long run. Via decomposition variance, it is obvious that a dynamic interaction of them exists. As for the decomposition variance of, the greatest contribution degree to change of the foreign direct investment is from itself $(87.563 \%)$. As for the decomposition variance of, the greatest contribution degree to change of GDP is from the foreign direct investment $(56.215 \%)$. As for the decomposition variance, the greatest contribution degree to change of the employment is from itself (85.419\%). In summary, the foreign direct investment still has a great power to force economic growth. And the impact of the economic growth to the inflow of economic growth presents a fluctuating trend. The reason is that there are some other factors such as the exchange rate fluctuation and the change of international market to affect the inflow of foreign direct investment. But as a whole, its effect is still positive. As for employment, the foreign direct investment has a promoted effect on employment in the long run. However, it has a negative effect on employment maybe due to the structural problem in the short run. All in all, in order to keep a rapid economic growth and a high employment level, government should take best use of foreign direct investment in China.

In summary, at present, China's government still should take measures to attract foreign investors to invest in China. The reason is that it can not only promote the economic growth but also it is beneficial to the employment 
in China. Moreover, China's government also should try its best to adjust the structure of employment so as to keep the high speed of economic growth. Additionally, China's government still should be regarded the economic growth as a most important task because it plays an important role in improving China's employment.

\section{References}

Bagli, S., \& Adhikary, M. (2014). FDI inflow and economic growth in India an empirical analysis. Economic Affairs, 59(1), 23. https://doi.org/10.5958/j.0976-4666.59.1.003

El-Wassal, K. A. (2012). Foreign direct investment and economic growth in Arab countries (1970-2008): An inquiry into determinants of growth benefits. Journal of Economic Development, 37(4), 79.

Kalirajan, K., Miankhel, A. K., \& Thangavelu, S. M. (2009). Foreign direct investment, exports, and economic growth in selected emerging countries: Multivariate VAR analysis.

Katircioglu, S. (2009). Foreign direct investment and economic growth in turkey: an empirical investigation by the bounds test for co-integration and causality tests. Ekonomska istraživanja, 22(3), 1-9.

Kersan-Škabić, I., \& Zubin, C. (2009). The influence of foreign direct investment on the growth of GDP, on employment and on export in Croatia. Ekonomski pregled, 60(3-4), 119-151.

Koojaroenprasit, S. (2012). The impact of foreign direct investment on economic growth: A case study of South Korea. International Journal of Business and Social Science, 3(21).

Mpanju, A. K. (2012). The impact of foreign direct investment on employment creation in Tanzania. International Journal of Business Economics \&Management Research, 2(1), 126-139.

Stylianou, T. (2014). Dynamic relationship between growth, foreign direct investment and exports in the US: an approach with structural breaks.

Suleiman, N. N., Kaliappan, S. R., \& Ismail, N. W. (2013). Foreign Direct Investments (FDI) and Economic Growth: Empirical Evidence from Southern Africa Customs Union (SACU) Countries. International Journal of Economics and Management, 7(1), 136-149.

Umoh, O. J., Jacob, A. O., \& Chuku, C. A. (2012). Foreign direct investment and economic growth in Nigeria: An analysis of the endogenous effects. Current Research Journal of Economic Theory, 4(3), 53-66.

Kim Seonsun, \& Kim Inji. (2016). A Study on the Impact of Inflow of FDI on Regional Economic Growth. The Northeast Asian Economic Association of Korea, 28(3), 85-114.

Ge Yufei. (2010). Research on the Impact of Employment Structure on Economic Growth. Modern Business, 5B, 171-171+.

He Renting, \& Xu Li. (2012). A Study on the Impact of FDI on Economic Growth. Journal of Anhui Agricultural University (Philosophy \& Social Sciences Edition), 21(6), 39-43.

Li Hong, \& Xu Yameng. (2017). Startup, Employment and Economic Growth: Application from China. Finance and Economy, 3, 37-40.

Wang Zhenlin. (2009). Influence of FDI on Economic Growth:Evidence From China. Journal of Jiangxi Science \& Technology Normal University, 4, 1-5.

Wang Xianxian. (2017). Analysis of Effective Interactive Mode Between Economic Growth and Employment Expansion. Economic Research Guide, 7,112-113.

Xie Kejin. (2014). Contribution of FDI to Economic Growth in Terms of Spatial and Temporal Difference. Forum of World Economics \& Politics, 6, 16-29.

Im Cheon, \& Jang Taegoo. (2013). A Study on the Impact of Foreigners' FDI on China's Economic Growth. Korean industrial Economic Association, 49-63.

\section{Copyrights}

Copyright for this article is retained by the author(s), with first publication rights granted to the journal.

This is an open-access article distributed under the terms and conditions of the Creative Commons Attribution license (http://creativecommons.org/licenses/by/4.0/). 